\title{
Community regulation by herbivore parasitism and density: Trait-mediated indirect interactions in the intertidal
}

\author{
Kim N. Mouritsen *, Sascha C.B. Haun \\ Department of Biological Sciences, Marine Ecology, University of Aarhus, Finlandsgade 14, DK-8200 Aarhus N, Denmark
}

\section{A R T I C L E I N F O}

\section{Article history:}

Received 4 July 2008

Received in revised form 26 September 2008

Accepted 8 October 2008

\section{Keywords:}

Bioturbation

Ecosystem engineering

Hydrobia ulvae

Zoobenthos

Microphytobenthos

Parasitic manipulation

\begin{abstract}
A B S T R A C T
The abundant herbivorous mud-snail Hydrobia ulvae is an ecosystem engineer in soft-bottom intertidal habitats due to its grazing and bioturbation activity. However, mud snails are commonly infected by trematodes that reduce their overall activity, which in turn may affect their impact on the surrounding benthic community. To test this hypothesis, we performed field experiments manipulating both the abundance of uninfected snails $\left(0,7500\right.$ and 15.000 ind. $\left.\mathrm{m}^{-2}\right)$ and the level of snail parasitism $(0,33$ and $100 \%$ trematode prevalence) on a Danish mud-flat. The results showed that increasing snail abundance and parasitism generally had opposite effects on the community of microphytobenthos and zoobenthos. Increasing snail density increased the chlorophyll- $a$ concentration in the substrate (enhancement), whereas increasing parasitism decreased it. In accordance, the benthic primary producers were generally less nutrient limited at high snail density and mostly so at high levels of snail parasitism. Moreover, epipsammic diatoms were favoured over epipelic diatoms at increasing snail density, whereas the opposite was evident at increasing snail parasitism. At the community level, increasing snail density increased evenness among epipelic diatoms, whereas increasing snail parasitism decreased evenness and species diversity. Probably through the action of trophic cascades and varying levels of disturbance, the zoobenthic community was influenced by experimental treatments as well. The indirect effects of snail parasitism influenced significantly the abundance of more faunal species (seven) than did snail density (two). At the community level, increasing snail density decreased evenness and lowest species richness coincided with intermediate snail density. In contrast, increasing snail parasitism resulted in increasing evenness and peaking species richness at intermediate level of parasitism. Together, the results show that parasites solely through their impact on the behaviour of a single community member can be significant indirect determinants of community organisation and function.
\end{abstract}

(c) 2008 Elsevier B.V. All rights reserved.

\section{Introduction}

Parasites are ubiquitous elements of natural communities with the potential to kill their host, either because of the pathology they inflict or because they facilitate trophic transmission and thereby host death (Scott and Dobson, 1989; Tompkins et al., 2002; Mouritsen and Poulin, 2002). Aside from such direct regulation of host populations, parasites may also indirectly influence community structure and function. For instance, if a competitively superior community member serves as host to a pathogenic parasite, the competitive release that follows from decreasing that host's abundance will ramify to the surrounding community. The parasite hence occupies a role similar to that of a keystone consumer (Power et al., 1996, see also Mouritsen and Poulin, 2002).

\footnotetext{
* Corresponding author. Tel.: +45 8942 4386; fax: +45 89424387.

E-mail address: kim.mouritsen@biology.au.dk (K.N. Mouritsen).
}

Whereas this community structuring role of parasites is increasingly recognized (e.g., Begon et al., 2006), supporting empirical evidence is largely confined to uncontrolled field observations and simple laboratory settings involving two closely related host species and their common parasite. Rarely, the indirect cascading effects have been considered to any great extent. Although such studies have been invaluable in demonstrating parasites' potential as community structuring agents, there is a need for field experiments evaluating also the indirect effects on natural communities.

The lack of controlled field experiments is hardly because such indirect effects are insignificant to community organisation, but rather related to problems associated with manipulation of parasitism in the field. Whereas host organisms may be successfully caged under natural settings, the minute size of their parasites' horizontally transmitted propagules makes it difficult to control the level of parasitism. A promising approach circumventing this obstacle is to focus, not on the density-mediated effects that follow from host population regulation at increasing parasite pressure, but on traitmediated effects (e.g. effect of changed host behaviour, see Trussell 
et al. 2003 and below cockle example). It is the rule rather than the exception that parasites change the behaviour of their host (Poulin, 2007). This usually involves changed activity levels, and in communities where such traits of dominating members play a structuring role (e.g. through interference competition), their parasites are likely to do so as well. The experimental advantage is that the parasites are caged together with the host individuals that harbour them. A field experiment that exploits this possibility involves echinostome trematodes and their intertidal cockle host, Austrovenus stutchburyi (Mouritsen and Poulin, 2005a, 2006). Heavily infected cockles are immobilised, unable to bury into the substrate when dislodged to the surface. This behavioural modification results in significant changes to the structure of the benthic community of plants and animals, mainly through the processes of sedimentation, facilitation and mitigated bioturbation. Wood et al. (2007) have similarly shown that the lower consumption rate of trematode-infected periwinkles Littorina littorea can affect the community structure of macroalgae on rocky shores.

Here, we extent the field experimental evidence that parasites indeed are potent community structuring agents. Focusing on the soft-bottom intertidal habitat, we use the small but abundant mud snail Hydrobia ulvae and associated trematode fauna as host-parasite system. Benthic microalgae and invertebrates act as the surrounding plant and animal community potentially influenced by the hostparasite interactions.

Depending on tidal level and the character of the substrate, H. ulvae may in rare cases reach densities of 300,000 individuals $\mathrm{m}^{-2}$ (Andersen, 2001). However, at average conditions adult abundance is generally $10-25,000 \mathrm{~m}^{-2}$ (e.g. Mouritsen et al., 1997). The species can constitute more than $80 \%$ of the total macrofaunal biomass and be the most important secondary producer; mud snails can therefore dominate energy flow (Reise, 1985). Because of the crawling activity while grazing on benthic diatoms, $H$. ulvae is also a potent bioturbator reworking the upper sediment strata several times a day even at moderate densities (Orvain and Sauriau, 2002). The resulting (1) increased surface roughness, (2) pelletation of the substrate that increases water content, and (3) down-grazing of sediment-stabilizing epipelic diatoms, are all processes that combine to cause erosion/ resuspension of the substrate and contained microphytobenhtos (Andersen, 2001; Andersen et al., 2002; Widdows and Brinsley, 2002; Orvain et al., 2003, 2006). So, although H. ulvae may not qualify as a key-stone species because of its high abundance, it may qualify as an ecosystem engineer (see Power et al., 1996; Meysman et al., 2006).

Along the west-coast of Europe, $H$. ulvae also functions as first intermediate host to more than 50 species of trematodes (Deblock, 1980). A range of macroinvertebrates and fish are used as second intermediate hosts, whereas shorebirds act as definitive hosts. In the snail population, the prevalence of infection show great temporal and spatial variation, but will during the active season often exceed $30 \%$ on tidal flats supporting high densities of definitive hosts (Mouritsen et al., 1997; Fredensborg, 2001, unpubl. data). One significant outcome of infection is an approximately 50\% reduction in the snails' overall crawling activity (Mouritsen and Jensen, 1994). This is a substantial impact of potentially great ecological importance, considering that the mud snail's role as an ecosystem engineer results largely from its bioturbation activity. We therefore hypothesized that the presence of trematodes in Hydrobia populations indirectly influences the surrounding benthic community by mitigating the mud snails' own density-dependent effects.

In order to test this hypothesis, we performed two simultaneously executed field experiments designed to determine (1) the impact of increasing parasite prevalence in experimental populations of $H$. ulvae on the community of benthic microalgae, meiofauna and juvenile macrofauna, and (2) the impact of increasing density of uninfected snails on the same community. Together these experiments allow an evaluation of the relative importance of parasite-induced trait-mediated and density-mediated effects on the intertidal benthic community.

\section{Materials and methods}

\subsection{Study area and snail collection}

Specimens of Hydrobia ulvae were collected during the summer of 2005 on an intertidal mudflat in the southern part of the Danish Wadden Sea $\left(54^{\circ} 56^{\prime} \mathrm{N}, 8^{\circ} 39^{\prime} \mathrm{E}\right)$, where also the field experiments were carried out. The area has a $1500 \mathrm{~m}$ intertidal zone, approximately $2 \mathrm{~m}$ tidal amplitude, and two low tides per 24 hrs. It is a homogenous flat of mixed sand and mud without significant macrovegetation.

The collected snails were kept in the laboratory in aquaria at $15^{\circ} \mathrm{C}$, with a substrate rich in diatoms as a food source. Trematode infected snails were identified by the shedding of cercariae. Snails were placed individually in small Petri dishes under light and at $18-26{ }^{\circ} \mathrm{C}$ for minimum 8 hrs, and released larval trematodes were identified according to Deblock (1980) under a microscope. To minimize the proportion of false negatives, this protocol was repeated for snails initially scored as uninfected. However, dissection of a sample of such 'uninfected' snails revealed a few percent immature infections. Although the group of uninfected snails was not entirely free of trematode infections, it will for simplicity be considered so in the following.

Uninfected snails and snails infected by different species of trematodes were counted in order to obtain the relative frequency distribution of the natural community of larval trematodes at the site of collection. The same frequency distribution was applied to infected snails added to all relevant experimental units (see below). The relative frequency distribution of the various infections was as follows: Cryptocotyle concava (Heterophyidae): $29 \%$ of infections; $\mathrm{Hi}$ masthla spp. (Echinostomatidae): 22\%; Maritrema spp. (Microphallidae): 35\%; Microphallus claviformis (Microphallidae): 14\% ( $n=931$ ). Other encountered infections (Notocotylidae spp. and Levinseniella carmarguensis (Microphallidae)) were rare and excluded in the experiment. An overall trematode prevalence of about $7 \%$ was found in the adult snail population at the time of collection.

\subsection{Experimental design}

The field experiments were carried out during 50 days in August and September in the mid intertidal, $600 \mathrm{~m}$ seaward from mean high water level. Five rows of eight experimental cages were placed parallel to the waterline, two meters apart, and displaced by one meter in every second row. Hence, each cage was placed four meters behind each other in relation to the tidal waterfront. This minimized interaction between cages due to hydrodynamic disturbance.

The cage was a transparent PVC cylinder, $20 \mathrm{~cm}$ in height and an inner diameter of $8 \mathrm{~cm}\left(50 \mathrm{~cm}^{2}\right.$ opening area). The lid was $6 \mathrm{~cm}$ high with $1 \mathrm{~mm}$ transparent polyethylene mesh on sides and on the top, allowing free exchange of meiofauna and juvenile macrofauna as well as more than $90 \%$ of the sun radiation to reach the sediment surface. Each cage was pushed into the sediment so that only the top three centimeters of the lid protruded above the sediment surface. Hence, the $50 \mathrm{~cm}^{2}$ experimental sediment surface was kept effectively drained through the mesh sides during low tide. The upper two centimeters of the natural sediment in each cage (where the majority of microalgae and meiofauna reside) were removed with a spoon and sieved through a $500 \mu \mathrm{m}$ screen into a large bowl in order to remove macrofaunal organisms. The sediment fraction passing through the mesh, and containing the natural populations of microalgae, meiofauna and juvenile macrofauna, was then gently homogenized and returned in even proportion to the 40 cages.

The removal of macrofauna from the upper sediment strata was justified firstly because the main target organisms were microalgae and meiofauna, and secondly because the naturally occurring adult population of hydrobiids had to be excluded (see below). The protocol also had the benefit of minimizing the pre-experimental variation in 
the structure of the benthic plant and animal community among cages and treatments.

Five different treatments were subsequently assigned to the 40 cages, fully randomized within the $5 \times 8$ block of cages: no Hydrobia ulvae added (No snails); 38 uninfected $H$. ulvae added (LD); 75 uninfected H. ulvae added (HD); 75 H. ulvae added of which $33 \%$ were infected by trematodes (HD33\%P); $75 \mathrm{H}$. ulvae added of which all were infected (HD100\%P). Hence, the experiment was composed of two separate but simultaneously executed parts: one that evaluated the effect of increasing density of uninfected snails (corresponding to zero, 7500 and 15,000 ind. $\mathrm{m}^{-2}$ ), and one that evaluated the effect of increasing trematode prevalence at the high snail density, the two parts sharing one treatment (HD). The planned sample size of eight per treatment became 7-9 because a HD-batch of snails was lost during establishment. This HD treatment was then reassigned to a 'No snails' treatment. The ideal full two-way design (i.e. also including parasite treatments at low snail density) was abandoned in order to save labour.

The experimental snail densities (LD and HD) correspond to natural abundances previously recorded at the experimental site (Mouritsen et al., 1997) and to the mean snail density measured just prior to the experiment (10,680 ind. $\mathrm{m}^{-2} ; n=10$, sampling area: $\left.50 \mathrm{~cm}^{2}\right)$. Moreover, the prevalence of trematode infections in intertidal species of gastropods (including hydrobiids) vary greatly on the temporal and spatial scale (zero to almost 100\%), and the prevalence in H. ulvae at the experimental site has been observed to exceed $50 \%$, and even $75 \%$ at other nearby sites (Mouritsen et al., 1997; Fredensborg, 2001; Poulin and Mouritsen, 2003, unpubl. data).

The mean $( \pm \mathrm{SE})$ shell height (apex to aperture) of experimental snails was $4.5( \pm 0.04) \mathrm{mm}$ (range: $3.3-6.5 \mathrm{~mm}, n=211)$. Based on shell measurements of a haphazardly selected subset of snails from each treatment, and in quantities equal to the number used in each treatment (38 and 75), showed that snails in the HD100\%P treatment were significantly larger ( $4.9 \mathrm{~mm}$ on average) than snails in the remaining treatments $(4.5 \mathrm{~mm})$ (Kruskal-Wallis test; all treatments together: $\chi_{3}^{2}=16.58, p<0.001$; the HD100\%P treatment excluded: $\left.\chi_{2}^{2}=0.90, p=0.64\right)$. This was expected and unavoidable because trematode infections in Hydrobia lead to gigantism (Mouritsen and Jensen, 1994). Although this size difference (9\%) is considered of minor importance, it means that the community effects recorded in the HD100\%P treatment cannot be ascribed solely to snail behaviour and cercarial release (see Discussion), but to a limited extent also the effect of snail size. However, this process works also under natural conditions and is not further addressed.

\subsection{Post-experimental sampling}

After the experiments, eight small core samples were taken on the caged sediment surface to a depth of $1.8 \mathrm{~cm}$ using modified plastic syringes $(\varnothing=1.2 \mathrm{~cm})$. Hence, $1.1 \mathrm{~cm}^{2}$ surface area and a sediment volume of $2.0 \mathrm{~cm}^{3}$ were retrieved by each sample. The samples were pooled two by two, producing four samples in total for each cage. Two of these samples were stored in plastic bags in a freezer (within three hours of sampling) for later sediment and chlorophyll- $a$ analysis, one was preserved in $4 \%$ buffered formalin for analysis of the metazoan community, and one was preserved in a lugol solution for diatom community analysis.

Following core sampling, the remaining substrate to a depth of $2 \mathrm{~cm}$ was retrieved from the cages and sieved through a $1 \mathrm{~mm}$ mesh to enumerate adult hydrobiids. The number of snails present in lids of cages was also recorded. This was done to elucidate whether snails were more prone to wander off the sediment in parasite treatments than in other treatments. The vertical position on the shore of many gastropod species is affected by trematode infections (e.g., Mouritsen and Poulin, 2002), and if this also applies to H. ulvae, the density of snails on the sediment may not have been similar in the three HD treatments during the experiment.

\subsection{Sediment analysis}

Core samples for sediment analysis were desiccated for two days in a drying cabinet and then dry sieved through a $2 \mathrm{~mm}$ mesh to remove larger molluscan shells. The organic material was then removed by oxidizing with $\mathrm{H}_{2} \mathrm{O}_{2}$ and heating. Following weighing, the sediment was separated into different size fractions (by wet-sieving) that were laser-diffracted using a Sympatec HELOS He-Ne laser (632.8 nm) (Rasmussen and Dalsgaard, 2005). This protocol allowed determination of organic content and particle composition of the substrate.

\subsection{Chlorophyll-a measurement}

The abundance of microphytobenthos (largely diatoms) in the sediment was estimated on the basis of chlorophyll- $a$ measurement (modified after Lorentzen, 1967). Each sediment sample was added to $20 \mathrm{ml} \mathrm{96 \%} \mathrm{ethanol} \mathrm{and} \mathrm{shaken} \mathrm{in} \mathrm{darkness} \mathrm{for} 12 \mathrm{hrs}$ at $15{ }^{\circ} \mathrm{C}$. The solution was then centrifuged at $4000 \mathrm{rpm}$ for $10 \mathrm{~min}$ after which the supernatant was pipetted into $1 \mathrm{~cm}$ spectrophotometer cuvettes, and the absorbance at 750 and $665 \mathrm{~nm}$ was measured both before and after addition of acid ( 3 drops of $1 \mathrm{M} \mathrm{HCL}$ ). The active chlorophyll- $a$ concentration $\left(\mu \mathrm{g} \mathrm{cm}^{-2}\right.$ ) was then calculated according to the formula:

$[$ Chlorophyll $-a]=\left(29.1\left(\mathrm{~A}_{\text {before }}-\mathrm{A}_{\text {after }}\right) * 20 \mathrm{ml}\right) /\left(2.2 \mathrm{~cm}^{2} * 1 \mathrm{~cm}\right)$

where $A_{\text {before }}-A_{\text {after }}$ gives the difference between the absorbance at 665 and $750 \mathrm{~nm}$ before and after addition of acid, respectively.

Also the absorbance at $480 \mathrm{~nm}$ was measured before adding acid in order to calculate the $480: 665 \mathrm{~nm}$ absorbance ratio. This ratio was used as a measure of the relative nutrient (nitrogen) limitation in the diatom community of the five different treatments (see Heath et al., 1990). The $480: 665 \mathrm{~nm}$ absorbance ratio reflects the carbon/nitrogen ratio in the microalgae, and in relative terms a high absorbance ratio indicates nitrogen deficiency.

\subsection{Diatom analyses}

To obtain data on the community structure of benthic microalgae, specimens of both epipelic and epipsammic diatoms were counted using a light microscope $(\times 160)$. The lugol-preserved sediment samples were thoroughly homogenized and a small sub-sample of each was smeared out on a microscope slide. Encountered diatoms were identified to the lowest possible taxonomic level and putative species.

For the epipelic diatoms (here, pennales and centrales combined) the procedure was to count all cells as well as any sand grains larger than about $0.06 \mathrm{~mm}$ in maximum dimension present in the field of vision, and proceed until c. 100 epipelic diatoms were counted. The generally smaller and much more abundant epipsammic diatoms attached to sand grains were counted (on the upper side of grains only) in a similar way until c. 800 cells were recorded. At the same time, all sand grains larger than $0.06 \mathrm{~mm}$ were enumerated for each processed field of vision. Sand grain counts were done to standardize for the amount of substrate processed and, in the case of epipsammic species, attachment sites. Based on these data, the relative frequency of both epipelic and epipsammic diatom species could be calculated. Because only a very small sediment sample was analysed from each cage, the list of encountered diatom species cannot be considered exhaustive. Epipelic and epipsammic diatoms were analysed separately due to the numeric dominance of the latter. Estimates of the different species relative contribution to the overall biomass of primary producers were based on maximum dimension and relative frequency.

\subsection{Fauna analyses}

The formalin preserved samples were dyed with Bengal Rose to stain organisms that were alive at the point of collection. Samples 


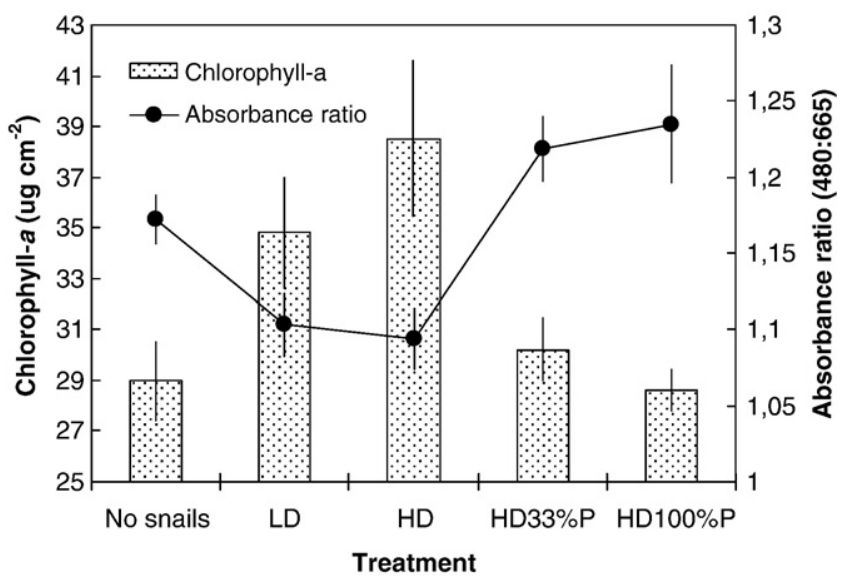

Fig. 1. Treatment effect on the active chlorophyll-a content $\left(\mu \mathrm{g} \mathrm{cm}{ }^{-2}\right)$ and the 480:665 nm pigment absorbance ratio in caged sediment (top $1.8 \mathrm{~cm}$ ) after the experiments. All values are means $( \pm \mathrm{SE})$. Treatments: No snails $=$ no Hydrobia ulvae added, LD (low density) $=38$ uninfected snails added per cage, HD (high density) $=75$ uninfected snails added per cage, HD33\%P = 75 snails added per cage of which $33 \%$ were infected by trematodes, HD100\% $=75$ snails added per cage, all of them infected. LD and HD density corresponded to 7500 and 15,000 mud snails $\mathrm{m}^{-2}$, respectively.

were sieved through four screens with mesh sizes of 500, 250,125 and $63 \mu \mathrm{m}$. The four resulting size fractions of animals were sorted out separately under a stereomicroscope. Metazoan species of meio- and (mainly juvenile) macrofauna were identified to varying taxonomic levels. The abundant nematodes were not attempted species identified, but separated into two groups (species complexes) according to the De Man ratio (body length/body width) (Platt and Warwick, 1988). One group had the ratio of 40-60 (nematode spp.1) and the other had a ratio larger than 100 (nematode spp. 2). Based on buccal armaments, the two groups of nematodes were tentatively assigned to two 'ecotypes' according to Tietjen (1969): nematode spp. 1 represents mainly predatory/omnivorous species whereas nematode spp. 2 are mostly grazers on microalgae. The different size fractions of animals were analysed separately. This was done because differently sized animals within a species complex may represent different species, and because small and large individuals may respond differently to experimental treatments.

\subsection{Data analyses}

The statistical analyses were carried out in SPSS. Parametric tests were preceded by evaluation of assumptions. If violated, data were ln-

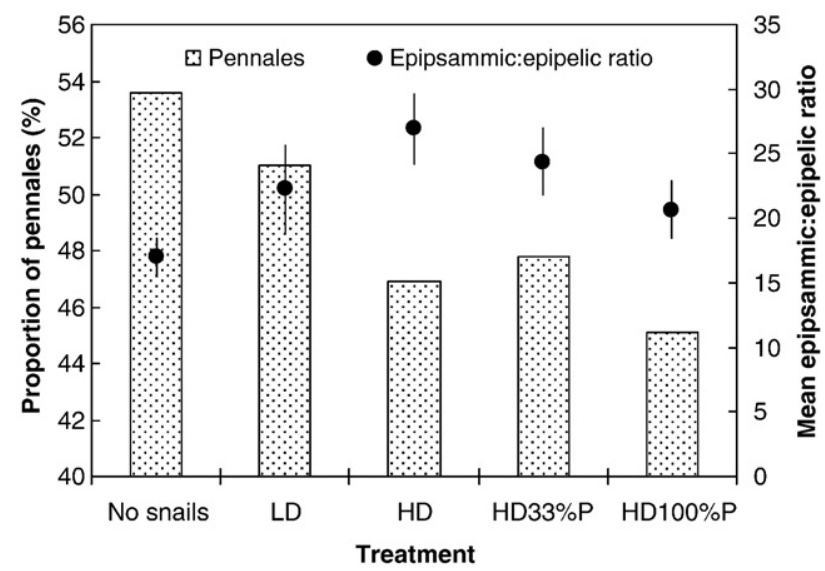

Fig. 2. Treatment effect on the proportion (\%) of pennate epipelic diatoms (all samples combined) and the mean $( \pm \mathrm{SE})$ epipsammic-to-epipelic diatom ratio in caged sediment (top $1.8 \mathrm{~cm}$ ) after the experiments. For a treatment account, see text to Fig. 1. or rank-transformed to meet assumptions or non-parametric tests were applied. Mean values on raw data in association with standard error (SE) are nevertheless given throughout although data were transformed or subject to non-parametric testing. In case of chisquare tests, categories with too few observations were either excluded or lumped together with adjacent categories to meet preconditions. Crosstabs refers to two-way contingency analysis. When data indicated a consistent trend in the relationship between the dependent variable and experimental treatment, regression analysis was in few cases used to optimize statistical power and to emphasize overall trend. Analyses were mostly carried out on the density series $\left(0,38\right.$ and 75 uninfected snails cage $\left.^{-1}\right)$ and the prevalence series (0, 33 and $100 \%$ infected snails) separately. However,
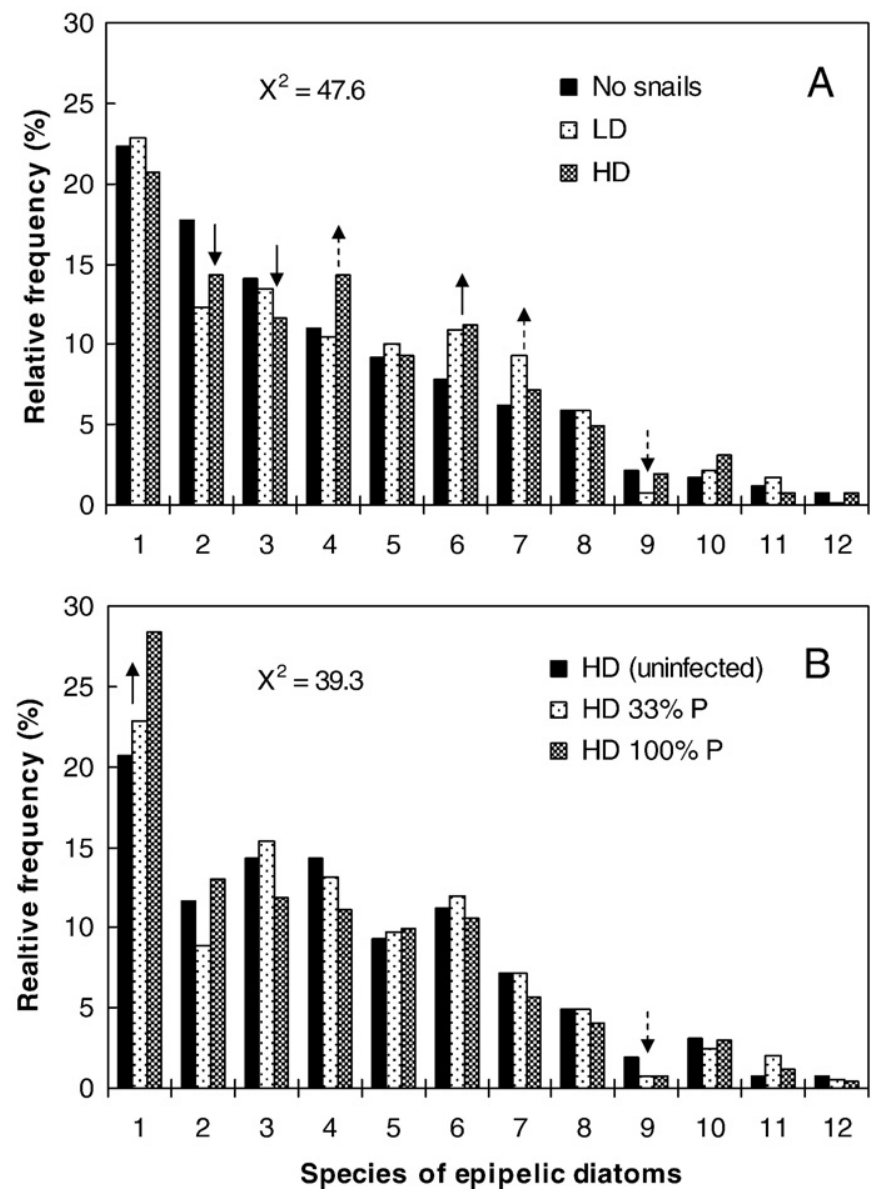

Fig. 3. Relative frequency (\%) of epipelic diatom species in caged sediment (top $1.8 \mathrm{~cm}$ ) exposed to (A) three different densities of uninfected mud snails Hydrobia ulvae (No snails $=$ no snails in cage $\left[50 \mathrm{~cm}^{-2}\right.$, LD [low density] $=38$ snails cage $\mathrm{e}^{-1}$, HD [high density] $=75$ snails cage ${ }^{-1}$ ), and (B) three different levels of trematode prevalence in the experimental population of mud snails (density $=75$ ind. cage $^{-1}$; HD (high density) $=$ all snails uninfected, HD33\%P $=33 \%$ of the snails infected by trematodes, $\mathrm{HD} 100 \% \mathrm{P}=$ all snails infected. Diatom species: (1) Melosira sp. (centrales, chain-forming), (2) Diploneis didyma (pennales), (3) Diploneis bombus (pennales), (4) Undatella spp. (pennales), (5) Actinoptychus splendens (centrales), (6) Paralia spp. (centrales), (7) Auliscus sculptus (centrales), (8) Amphora copulate (pennales), (9) Amphora ostrearia (pennales), (10) Brockmanniella sp. (pennales, chain-forming), (11) Pleurosigma augulatum (pennales), (12) Odontella aurita (centrales, chain-forming). Species not included due to infrequent occurrence: Nitzschia sigma (pennales) and Amphora sp. (pennales). Chi-square values from the overall crosstabulations are inserted. Full arrows indicate those species that depart significantly (here, $0.005 \leq p \leq 0.043$ ) from an even across-treatment frequency distribution in individual Goodness-of-fit tests, and broken arrows denote marginally significant trends (here, $0.062 \geq p \geq 0.054$ ). Up- and down-pointing arrows denote increase and decrease as a function of increasing snail density or prevalence of infection, respectively. Species are listed according to their relative frequency in the 'No snails' treatment. The different species contribution to the total biomass (volume) of epipelic diatoms (pennales and centrales combined) generally corresponds to their relative frequency, with the exception of Melosira sp. (species 1 ) that equals species 5 . 

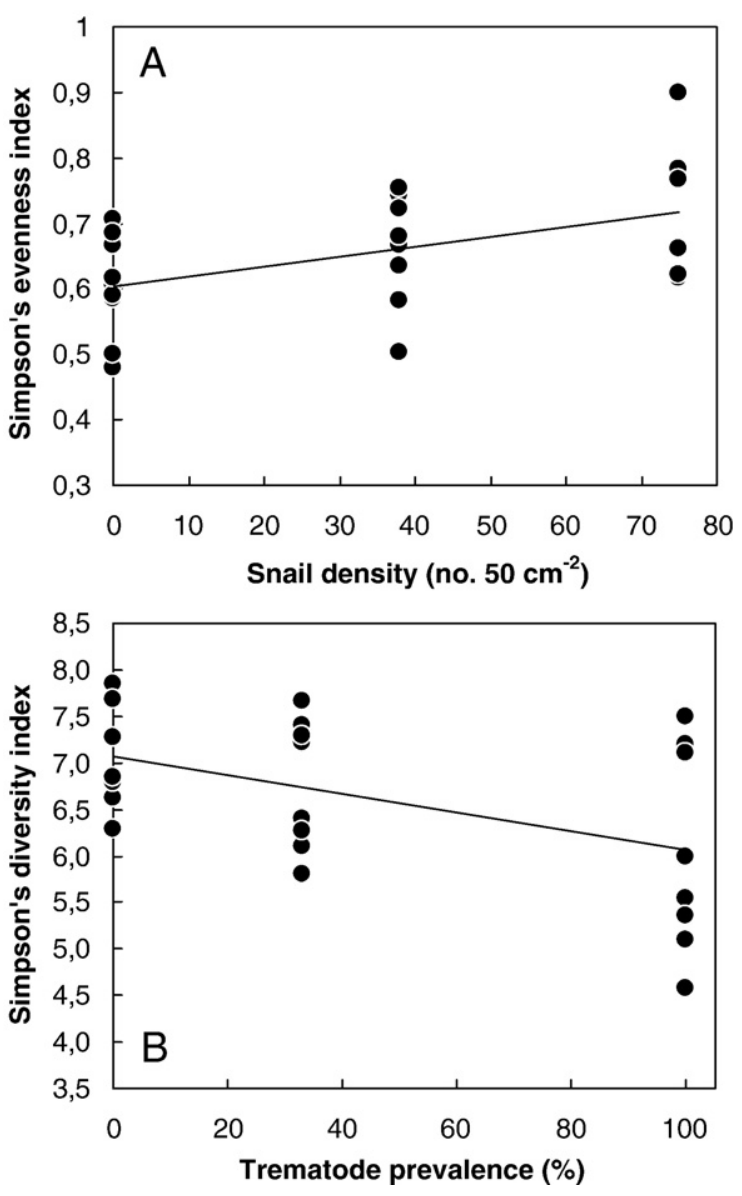

Fig. 4. Epipelic diatoms (pennales and centrals combined): (A) Simpson's evenness index (1/Ds) as a function of uninfected snail density (Hydrobia ulvae); linear regression, $r_{22}^{2}=0.233, p=0.017$. (B) Simpson's index of diversity (1/D) as a function of the prevalence of infection in experimental snails (75 Hydrobia ulvae cage $^{-1}$ ); linear regression, $r_{21}^{2}=0.230, p=0.021$. The $\mathrm{y}$-axis unit is species in both panels (see Materials and methods).

when convenient for comparative purposes all data were analysed and illustrated together. Regarding response of species and diversity indices (see below) on treatments, only those significantly affected are dealt with in Results.

Four diversity measures were calculated according to Krebs (1999): Simpson's diversity index emphasizing common species $\left(1 / D, D=\sum p_{i}^{2}\right.$, $\mathrm{p}_{\mathrm{i}}=$ proportion of species $i$ in the community), Shannon-Wiener index emphasizing rare species $\left(2^{\mathrm{H}}, \mathrm{H}=-\sum \mathrm{p}_{\mathrm{i}} \log \mathrm{p}_{\mathrm{i}}\right)$, Simpson's measure of evenness (1/Ds, $s=$ number of species in the sample), and species richness (s). The unit of both diversity indices is 'species', which indicates the number of equally abundant species necessary to obtain the diversity actually observed in the samples (see Krebs, 1999). Because of development of thread-algae mats (siphonocladales) in four cages, these were excluded as outliers in the analysis of chlorophyll- $a$ data used as a proxy of microalgal abundance. This reduced the sample size to 6-8 per treatment in this case.

\section{Results}

\subsection{Mortality, recruitment and behaviour of snails}

Based upon 95\% confidence limits, the number of snails retrieved from the cages was similar to the number added, suggesting a low mortality rate during the experiment. However, the mortality may have been somewhat higher because juvenile snails have grown into the macrofaunal size-fraction (here $>1 \mathrm{~mm}$ ), and thereby elevated post-experimental snail density. Because juvenile hydrobiids are rarely infected by trematodes (pers. obs.), this also means that the prevalence of infection in the two parasite treatments has been lower than planned toward the end of the experiment. Based on the abundance of such younger and presumably uninfected snails, the trematode prevalence declined during the experiment from 33 to about $30 \%$ in the HD33\%P treatment, and from 100 to $91 \%$ in the HD100\% treatment.

Disregarding the 'No snails' treatment, the proportion of experimental snails encountered in lids of cages was statistically similar among treatments (on average 7\%; One-way ANOVA on arcsintransformed data, $\left.F_{3,27}=1.25, p=0.31\right)$. This shows that the snails' tendency to move onto lids of cages was unaffected by parasitism, and that the experiment succeeded in keeping a common density of snails on the sediment surface in all three HD treatments.

\subsection{Sediment characteristics}

All sediment characteristics measured (organic content, median particle diameter, sorting coefficient and clay, silt and sand content) proved to be statistically unaffected by treatments (data not shown;
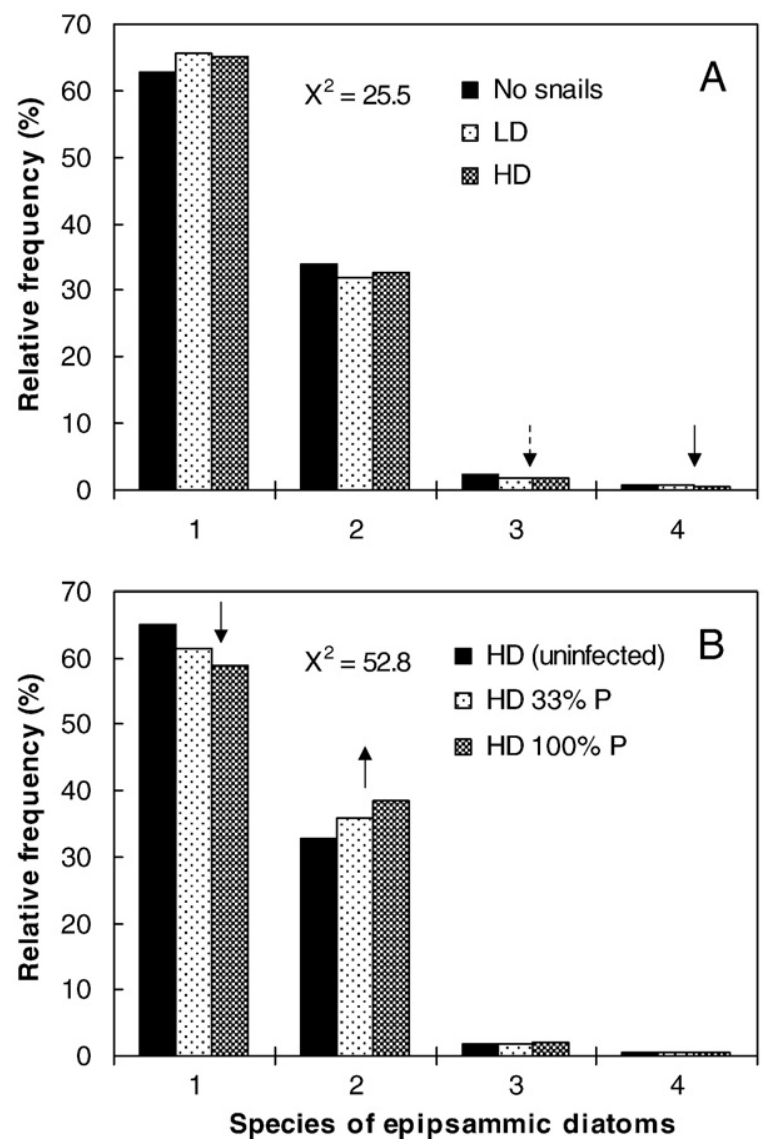

Fig. 5. Relative frequency (\%) of epipsammic diatom species in caged sediment (top $1.8 \mathrm{~cm}$ ) exposed to (A) three different densities of uninfected mud snails Hydrobia ulvae and (B) three different levels of trematode prevalence in the experimental population of mud snails (for treatment account, see text to Fig. 3). Diatom species (all pennales): (1) Catenula adhaerens (chain-forming), (2) Achnanthes spp., (3) Pseudostaurosira sp. (4) Martyana spp. Chi-square values from the overall cross-tabulations are inserted. Full arrows indicate those species that depart significantly (here, $p<0.003$ ) from an even across-treatment frequency distribution in individual Goodness-of-fit tests, and broken arrows denote marginally significant trends (here, $p=0.054$ ). Up- and down-pointing arrows denote increase and decrease as a function of increasing snail density, or prevalence of infection, respectively. Species are listed according to their relative frequency in the 'No snails' treatment. The four species contribution to the total biomass (volume) of epipsammic diatoms generally corresponds to their relative frequency. 
One-way ANOVA, $F_{4,35} \leq 1.38, p \geq 0.26$ for all parameters). This demonstrates that observed treatment effects on the benthic community (see below) were not mediated by altered properties of the substrate.

\subsection{Chlorophyll-a content and nutrient limitation}

As a measure of benthic microalgae abundance, the chlorophyll- $a$ content of the sediment showed statistically significant variation among treatments (One-way ANOVA, $F_{4,30}=4.71, p=0.005$ ) (Fig. 1). Chlorophyll- $a$ increased with increasing snail density (up to $33 \%$ ), although LSD post hoc tests showed that the difference between LD (low density) and HD (high density) was non-significant $(p=0.18$ ). Opposed to increasing snail abundance, increasing prevalence of trematodes at high snail density (HD) decreased the chlorophyll- $a$ content of the substrate by $22-26 \%$ (Fig. 1). However, post hoc tests indicated no significant difference between the two parasite treatments $(p=0.57)$.

The 480:665 $\mathrm{nm}$ absorbance ratio showed a significant pattern opposite to the chlorophyll- $a$ content (One-way ANOVA, $F_{5,34}=7.32$, $p<0.0005$ ) (Fig. 1). The ratio was significantly higher in absence than in presence of snails (LSD post hoc test: $L D$ versus No snails, $p=0.026$; HD versus No snails, $p=0.032$; LD versus HD, $p=0.80$ ). In contrast, the absorbance ratio was significantly higher (less nitrogen available) in treatments with infected than uninfected snails (Fig. 1; HD versus HD33\%P, $p=0.001$; HD versus HD100\%P, $p<0.0005$; parasite treatments contrasted, $p=0.64$ ).

\subsection{Diatom community structure}

Twelve epipelic (pennales and centrales combined) and four epipsammic species of diatoms were recorded; Melosira sp. and $\mathrm{Ca}$ tenula adhaerens being the most prevalent species, respectively (see text to Figs. 3 and 5 for a list of species). Overall, epipsammic diatoms outnumbered epipelic diatoms by a factor 22 , and contributed by more than $75 \%$ of the biomass (by volume).
The epipsammic-to-epipelic ratio differed significantly between treatments (rank-transformed data, One-way ANOVA, $F_{4,35}=2.77$, $p=0.042$ ), showing an increasing trend with increasing snail density and a decreasing trend with increasing prevalence of infection (Fig. 2). Furthermore, the relative proportion of pennate and centric forms in the group of epipelic diatoms was also significantly influenced by treatment (Fig. 2, Crosstabs, $\chi_{4}^{2}=16.21, p=0.003$ ): the proportion of pennales decreased as a function of snail density $\left(\chi_{2}^{2}=8.03, p=0.018\right)$, whereas increasing trematode prevalence at high snail density had no effect on the proportion of pennate diatoms $\left(\chi_{2}^{2}=1.22, p=0.54\right)$.

\subsubsection{Epipelic diatoms}

Snail density significantly affected the relative frequency of epipelic diatom species (Fig. 3A; all treatments: Crosstabs, $\chi_{11}^{2}=47.61$, $p=0.001$; No snails versus LD: $\chi_{11}^{2}=19.45, p=0.053$; No snails versus HD: $\chi_{11}^{2}=30.26, p=0.001$; LD versus HD: $\left.\chi_{11}^{2}=23.56, p=0.015\right)$. Particularly the pennate Diploneis bombus and $D$. didyma responded negatively on the presence of snails $\left(\chi_{2}^{2}>8.50, p<0.014\right)$, and they may hence be the species preferred by $H$. ulvae as a food source. The centric Paralia spp. was the only species-group significantly favoured by snail presence $\left(\chi_{11}^{2}=6.27, p=0.043\right)$. However, also Auliscus sculptus and Undatella spp. tended to be positively affected ( $p=0.054$ and 0.062 , respectively) (Fig. 3A).

The prevalence of trematode infections in experimental snails also affected the frequency of epipelic diatom species (Fig. 3B; all treatments: Crosstabs, $\chi_{22}^{2}=39.32, p=0.013$; HD versus HD33\%P: $\chi_{11}^{2}=$ 13.13, $p=0.29$; HD versus HD100\%P: $\chi_{11}^{2}=22.46, p=0.021$; HD33\%P versus HD100\%P: $\chi_{11}^{2}=21.83, p=0.026$ ). Most species tended to be negatively affected by increasing parasite prevalence, and the chainforming Melosira sp. was the only species particularly positively affected $\left(\chi_{2}^{2}=10.49, p=0.005\right)$ (Fig. 3B). So, although increasing snail density and parasitism at high snail density exerted a quantitatively comparable effect on the relative frequency of epipelic diatom species (see overall chi-square values inserted in Fig. 3), there were qualitative differences in terms of species affected.
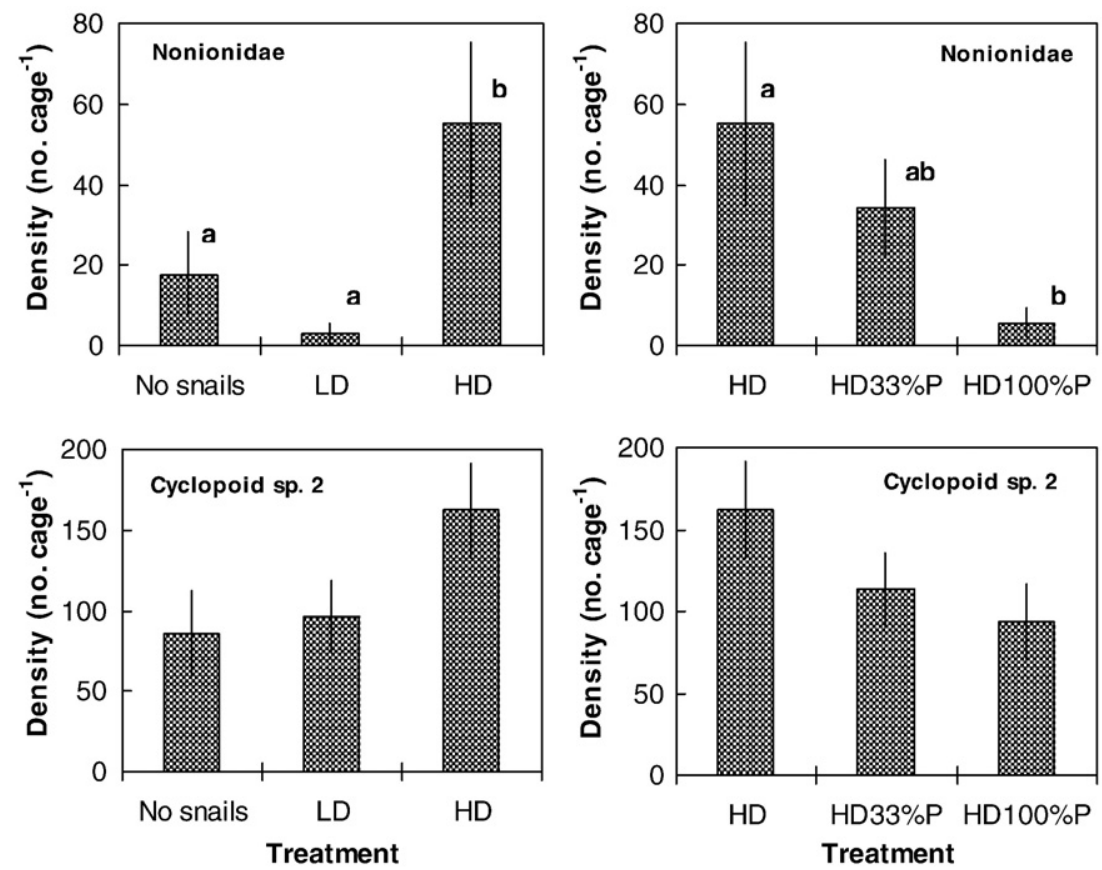

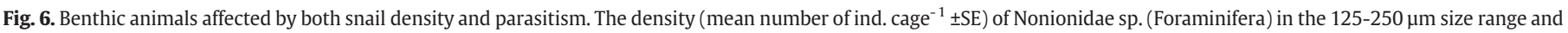

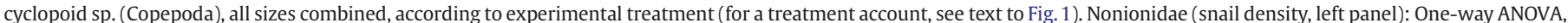

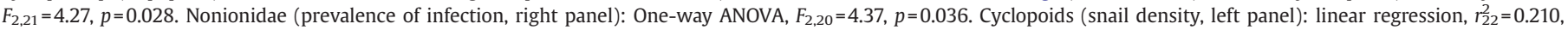

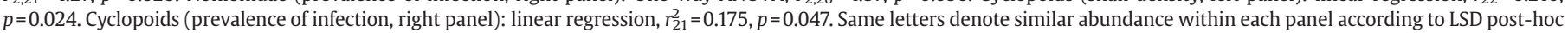
tests $(p \geq 0.05)$. All analyses were carried out on rank-transformed data. 
At the community level, Simpson's evenness index for epipelic diatoms increased significantly (up to 20\%) with increasing density of uninfected snails (Fig. 4A). This follows from the relative decrease of the two common Diploneis species and increase of more rare genera such as Paralia, Auliscus, Undatella and Brockmanniella; see Fig. 3A). Other diversity measures were unaffected by snail density. In contrast, increasing parasite prevalence at high snail density influenced negatively both Shannon-Wiener's (emphasising rare species, 11\% decrease, data not shown) and Simpson's (emphasising common species, 17\% decrease, Fig. 4B) diversity index as well as Simpson's evenness index (17\% decrease, data not shown). The substantial increase with parasitism in the relative abundance of the common Melosira sp. (see Fig. 3B) contributes to this pattern.

\subsubsection{Epipsammic diatoms}

The relative frequency of also the four epipsammic diatom species differed between snail density treatments (Fig. 5A; all treatments: Crosstabs, $\chi_{6}^{2}=25.46, p<0.0005$; No snails versus LD: $\chi_{3}^{2}=14.46$, $p=0.002$; No snails versus HD: $\chi_{3}^{2}=19.40, p<0.0005$; LD versus HD: $\chi_{3}^{2}=3.72, p=0.29$ ). However, tests of individual species showed that only the most infrequent species-group (Martyana spp.) was significantly influenced (negatively) by increasing snail density (Goodness-of-fit, $\chi_{2}^{2}=11.67, p=0.003$ ). Also the rare Pseudostaurosira sp. tended to be negatively affected $(p=0.054)$.

As for changing snail density, increasing trematode prevalence at high snail density influenced the relative frequency of epipsammic diatoms (Fig. 5B; all treatments: Crosstabs, $\chi_{6}^{2}=52.84, p<0.0005$; all pair-wise comparisons: $\left.\chi_{3}^{2}>10.48, p<0.016\right)$. However, as opposed to the effect of snail density, increasing parasite prevalence influenced only the two most frequent species/species-groups (Achnanthes spp. and Catenula adhaerens). Achnanthes was positively affected (Goodness-offit test, $\left.\chi_{2}^{2}=30.00, \mathrm{p}<0.0005\right)$ whereas Catenula was negatively affected $\left(\chi_{2}^{2}=19.69, p<0.0005\right)$ by increasing parasitism. Quantitatively, the epipsammic community seemed more sensitive to changes in snail parasitism than snail density, evidenced by the more than twice as high chi-square value from the overall cross-tabulation of the former (see inserts in Fig. 5).

None of the applied diversity measures were significantly affected by experimental treatments. Considering the low number of epipsammic species (four), this is to be expected.
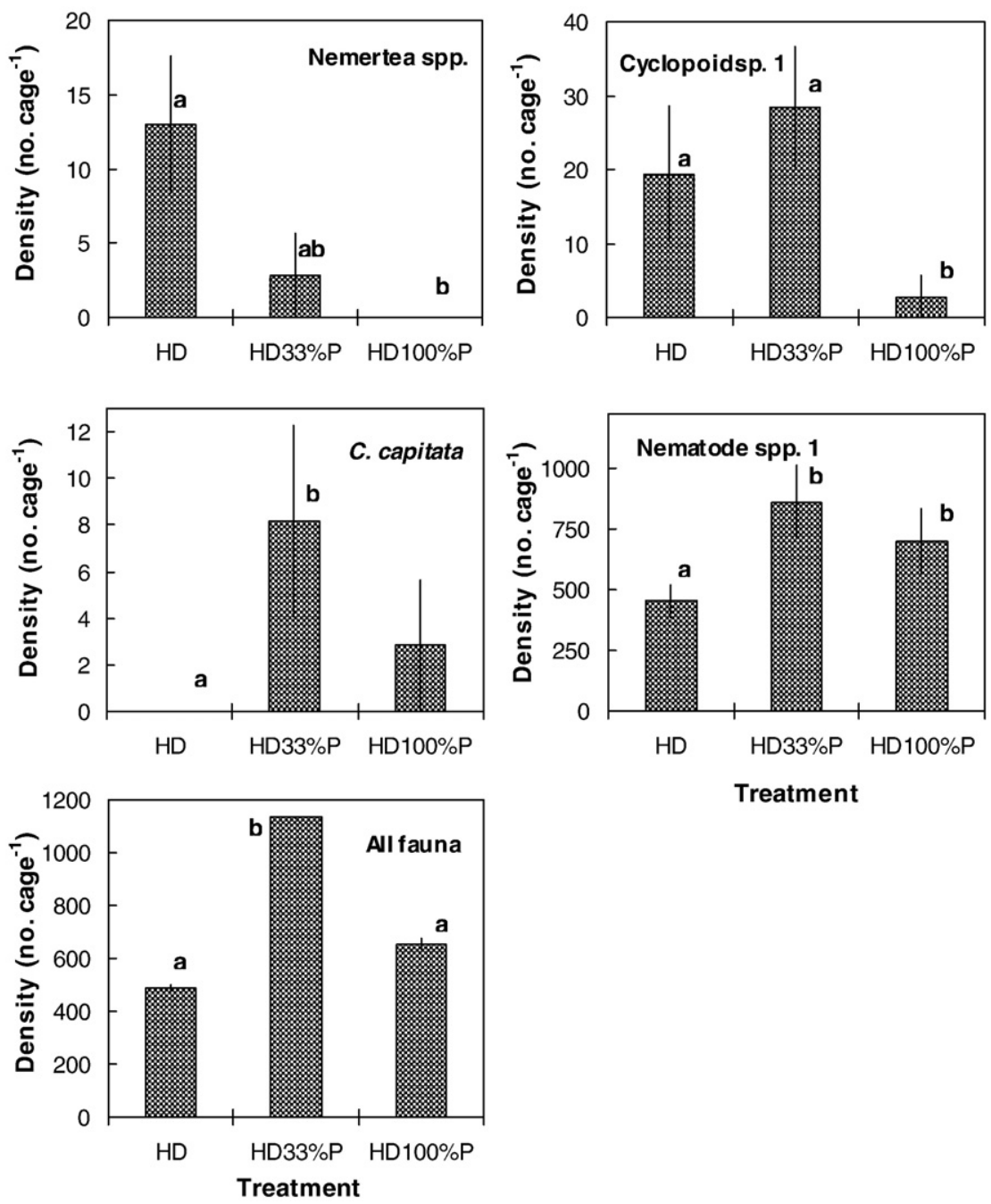

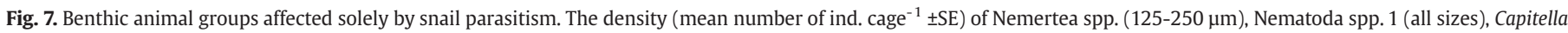

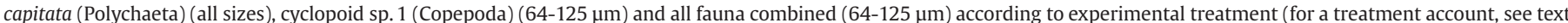

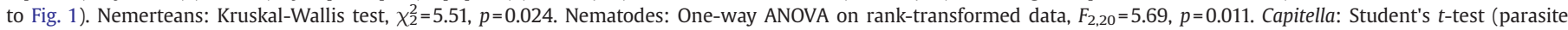

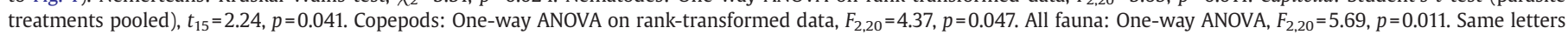
denote similar abundance within each panel according to appropriate post-hoc tests $(p \geq 0.05)$. All ANOVA's were carried out on rank-transformed data. 


\subsection{Faunal community structure}

Twenty-six species/species-groups of benthic metazoans (mainly meiofauna and juvenile macrofauna) were recorded, several of which occurred solely in certain experimental treatments or size classes (see Appendix 1). Of those, two meiofaunal species, Nonionidae sp. (Foraminifera) and cyclopoid sp. 2 (Copepoda), were affected both by increasing snail density (positively) and parasitism (negatively) thereby mirroring the data on chlorophyll-a content (Fig. 6, compare with Fig. 1). The remaining five species/species groups influenced by experimental treatment were so solely by the level of parasitism (Fig. 7). Three patterns emerge as a function of parasitism: decreasing abundance (Nemertea spp. and cyclopoid sp. 1, as seen also in Nonionidae and cyclopoid sp. 2), increasing abundance (Capitella capitata and nematode spp.1) and peaking abundance at intermediate trematode prevalence (all fauna combined) (Fig. 7). None of the animal species affected by parasitism acts as host to the trematodes included in the experiment.

At the community level, Simpson's evenness index decreased (up to $40 \%$ ) with increasing snail density (Fig. 8A). However, this was statistically significant only for animals in the $125-250 \mu \mathrm{m}$ size class. Species richness reached a minimum at intermediate snail density (Fig. 8B). The opposite pattern was evident for increasing parasitism at high snail density: Simpson's evenness index increased by up to $32 \%$ with increasing prevalence of infection (Fig. 9A), whereas species richness peaked at intermediate prevalence (Fig. 9B). The latter was
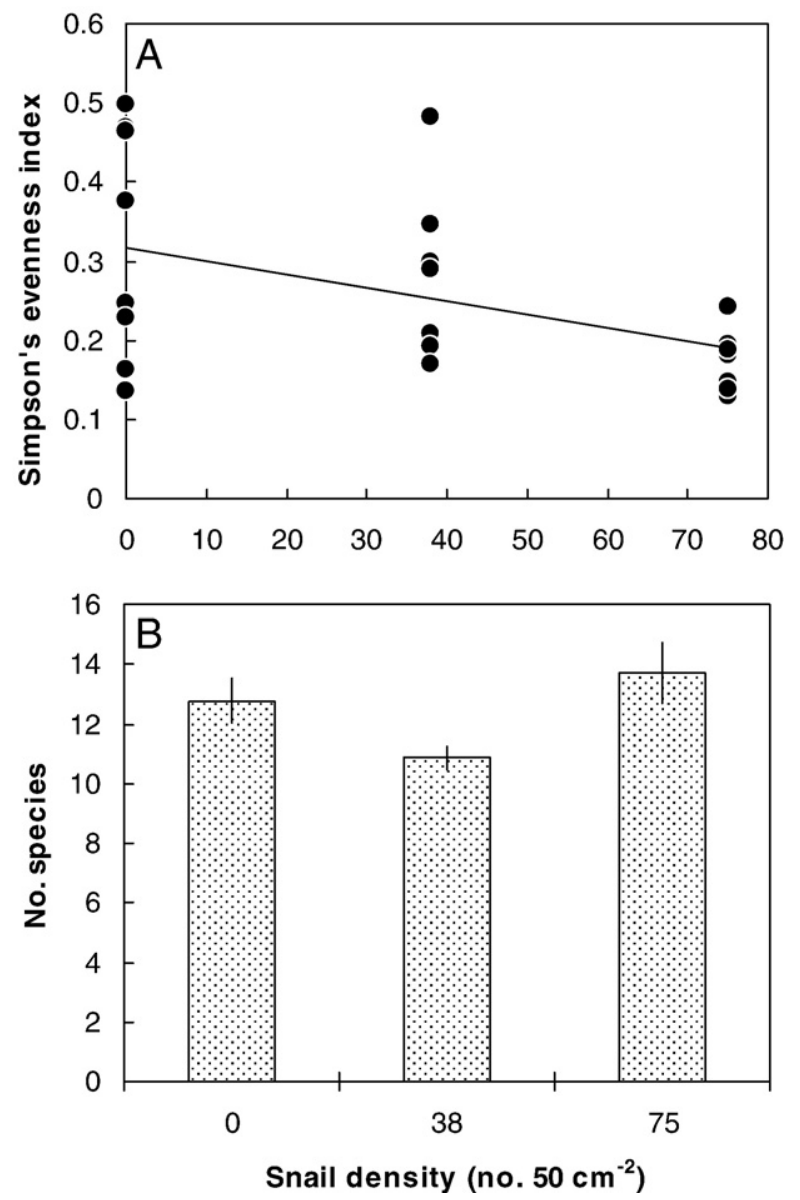

Fig. 8. Relationships between diversity measures for the faunal community and the density of uninfected experimental snails (Hydrobia ulvae). (A) Simpson's evenness index (1/Ds) for animals in the $125-250 \mu \mathrm{m}$ size range (linear regression on $\mathrm{ln}$ transformed data, $\left.r_{21}^{2}=0.194, p=0.035\right)$. (B) Mean number of animal species $( \pm \mathrm{SE}$ ), all size ranges combined (One-way ANOVA on rank-transformed data, $F_{2,21}=3.71$, $p=0.042$ ). See Appendix 1 for a list of species/species groups according to size range.
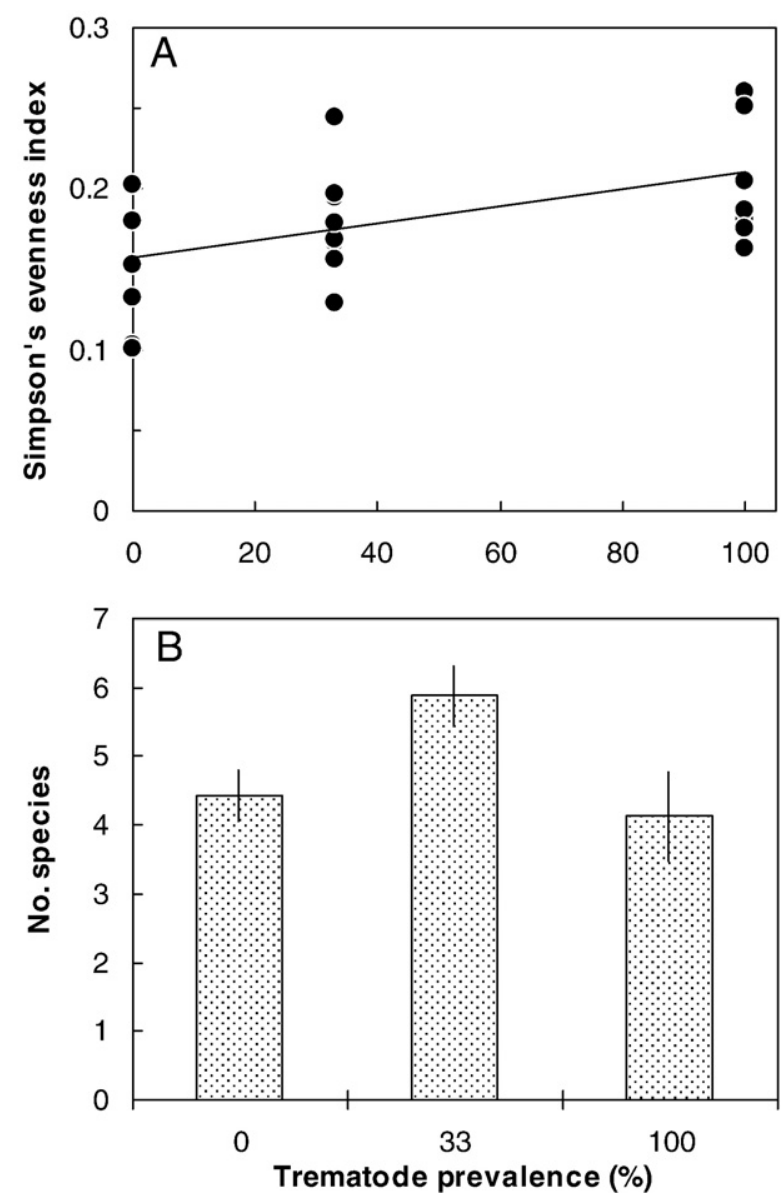

Fig. 9. Relationships between diversity measures for the faunal community and the prevalence of infection in experimental snails ( 75 Hydrobia ulvae cage ${ }^{-1}$ ). (A) Simpson's evenness index (1/Ds), all size ranges combined (linear regression on rank-tranformed data, $r_{21}^{2}=0.281, p=0.009$ ). (B) Mean number of animal species $( \pm \mathrm{SE})$ in the $64-125 \mu \mathrm{m}$ size range (One-way ANOVA on rank-transformed data, $F_{2,20}=3.89, p=0.037$ ). See Appendix 1 for a species list according to size range.

statistically significant only for animals in the 64-125 $\mu \mathrm{m}$ size class, though.

\section{Discussion}

The present results demonstrate that both snail density and parasitism influences the community structure of benthic primary and secondary producers, mainly through trait-mediated indirect effects (i.e. through changed level of bioturbation by snails). However, the impact of herbivore abundance and parasites is both qualitatively and quantitatively different.

\subsection{Abundance of primary producers}

Increasing abundance of the (uninfected) herbivorous mud snails results in increasing chlorophyll- $a$ levels in the substrate. This suggests that within the applied experimental density range, snails enhance the benthic community of primary producers rather than exerting top-down control. Interestingly, increasing prevalence of infection at high snail density resulted in the opposite: a notable decrease in the chlorophyll- $a$ concentration, clearly evident even at the moderate and for in situ conditions more common trematode prevalence (33\%, see Fig. 1). In fact, posing trematode-infections upon an averagely dense population of adult $H$. ulvae $\left(15,000\right.$ ind. $\left.\mathrm{m}^{-2}\right)$ results in a biomass of benthic primary producers that equals a situation where there are no snails present at all. There may be several 
not mutually exclusive explanations for this, among which we particularly favour two supported by our results.

(1) The bioturbation activity exerted by increasing snail density releases nutrients from the substrate, which elevates primary production and, in turn, the standing stock of microalgae (see e.g. Dyson et al., 2007). Similarly, the relaxed sediment disturbance that follows from increasing trematode prevalence in the experimental population of snails (see Mouritsen and Jensen, 1994) decreases this rate of nutrient release, causing a decline in microalgal biomass. The 480:665 nm absorbance ratios support this interpretation, as the relative nutrient limitation decreases with increasing snail density and increases with increasing parasite prevalence (Fig. 1). So, the parasites indirectly influence the amount of nutrients (nitrogen) available for the primary producers.

(2) Bioturbation benefits the dominating epipsammic diatoms by exposing them to sunlight on a regular basis (by re-emerging sand grains on which these diatoms are attached), and thereby increases their vertical zone of growth in the substrate. In little or undisturbed sediments, the epipsammic diatoms may grow only on sand grains positioned at the very surface of the substrate. Accordingly, the epipsammic:epipelic ratio was found to increase with increasing snail density and decrease with increasing trematode prevalence (Fig. 2).

Both of the above two processes (nutrient release and facilitation/ inhibition of epipsammic diatoms) have likely been in action consecutively, as crude calculations indicate that the latter process is insufficient to account for the change in microalgal biomass (chlorophyll- $a$ ) across treatments. Although it may be unwise to focus on exact values rather than overall trends, the surprisingly low chlorophyll- $a$ content in the HD33\%P treatment (equalling the 'No snails' treatment, see Fig. 1), may be justified by meiofaunal top-down control (see Blanchard, 1991; Montagna et al., 1995; Epstein, 1997; Buffan-Dubau and Carman, 2000) as the abundance of meiofauna peaks in this treatment (Fig. 7).

\subsection{Diatom community structure}

Although increasing snail density and parasite prevalence caused a quantitatively similar change in the frequency distribution of epipelic diatoms, there were qualitative differences in terms of species affected. Probably through direct consumption, increasing snail density depressed the relative proportion of some of the most frequently occurring pennate diatoms (particularly Diploneis spp.), mirrored also in the decreasing proportion of pennales with snail density (Fig. 2). Because the consumption rate of infected and uninfected Hydrobia ulvae is similar (Mouritsen and Jensen 1994), and because there is currently no evidence suggesting a difference in selection of diatom species, the unchanged proportion of pennales with increasing parasite prevalence (Fig. 2) is expectable. Still, the overall frequency distribution of microalgae was strongly affected by parasitism in that particularly the dominant Melosira sp. was favoured by increasing trematode prevalence. Maybe this chain-forming species, growing on the very surface of the sediment, is favoured by nutrients regenerated directly in the water-sediment interface from deposited dead trematode larvae. These larvae are continuously released from infected snails, and although their small size $(<0.5 \mathrm{~mm})$ allows them to escape from the cages, some may have remained.

Alternatively, Melosira might be favoured by a high porosity of the surface sediment that follows from the snails' pelletation of the substrate, aside from reduced disturbance at increasing levels of parasitism. In any case, the changes in frequency distribution of epipelic diatoms translate into an effect on diversity indices: evenness increased with snail density (Fig. 4A) because of grazing on common species, and decreased with parasitism (data not shown) mainly because the most common species (Melosira) was indirectly favoured. Because species richness was unaffected by treatments, species diversity should follow the pattern in evenness. However, only the negative relationship between diversity and parasitism could be demonstrated statistically significant (Fig. 4B). Hence, in terms of species diversity in the community of epipelic diatoms, we reach the surprising conclusion that a density range of 15,000 grazers $\mathrm{m}^{-2}$ has no measurable effect, whereas trematode infections in an intermediately dense snail population results in significantly reduced diversity.

The epipsammic diatoms support this picture: the indirect effect of parasitism overrides that of herbivore density (Fig. 5), and the relative frequency of the two most abundant species (Catenula adhaerens and Acnanthes spp.) was significantly influenced only by increasing parasite prevalence. Snail density, in contrast, had minor effect solely on the most infrequent species, Martyana spp. and Pseudostaurosira $\mathrm{sp}$. The processes governing these patterns remain unknown, but probably involve the combined effect of selective grazing by the hydrobiids (that feed also on epipsammic diatoms), and species specific responses to bioturbation and nutrient availability.

\subsection{Faunal community}

Turning to the faunal responses, there is evidence of a trophic cascade/functional response. The abundance of the respectively detrivorous and herbivorous Nonionidae (Foraminifera) and cyclopoid sp. 2 (Copepoda) tend to correlate positively with chlorophyll- $a$ levels across treatments (compare Figs. 1 and 6). However, it can not be ruled out that these organisms are sensitive also to changed bioturbation activity. Aside from these animals affected by both snail density and parasitism, the abundance of other affected species/species groups were so solely by changing prevalence of infection (Fig. 7). However, the responses are mixed in that decreasing, increasing and peaking trends are evident as a function of parasitism. Our experiments were not designed to identify underlying processes, but neither the abundance of primary producers nor the level of disturbance can account for these effects per se. If so, there would have been an effect of snail density as well. An influential factor may be the presence of trematode larvae (cercariae) released by infected snails in parasite treatments. These cercariae may serve as food to oligochaetes and polychaetes (Fernandez et al., 1991, Rodgers et al., 2005, A. Kuris, pers. com.), and likely also to predatory/omnivorous meiofauna. This might have affected abundance through increased survival or functional response. In accordance, the polychaetes Capitella capitata was found solely in parasite treatments, and the predatory/omnivorous nematode spp. 1 reached highest densities in these treatments (Fig. 7). The overall peaking tendency in the abundance of fauna as a function of prevalence (Fig. 7, last panel) could likewise be caused partly by a cercarial food supply in combination with relaxed disturbance levels. Evidence suggests the latter to benefit meiofaunal communities (Widdicombe and Austen, 1999; Tita et al., 2000; Austen and Widdicombe, 2006).

Whatever processes involved, changing snail density and trematode prevalence resulted in qualitatively different impacts on faunal community structure, opposite that observed for the microalgae: evenness decreased as a function of snail density and increased as a function of trematode prevalence (Figs. 8A and 9A). Moreover, species richness reached a minimum at intermediate herbivore density, but peaked at intermediate prevalence of infection (Figs. 8B and 9B). Hence, snail parasitism exerts an indirect positive influence on the diversity of benthic secondary producers, particularly at an intermediate level of parasitism.

\subsection{Conclusions and perspectives}

To our knowledge, the present study is the first field experiment to demonstrate the significance of trait-mediated indirect effects of 
herbivore parasitism on an almost full community of primary and secondary producers. In addition, the experiments allowed a comparison of the isolated effect of primarily behavioural aspects of parasitism on one side, and the effect of changes in herbivore host population density on the other. Although not directly comparable due to different units (density and prevalence), this comparison arrives at the intriguing conclusion that albeit the community-wide impact of the two processes is quantitatively in the same order of magnitude, the effect of parasitism generally overrides that of host density.

Importantly, because increasing host density and parasitism generally showed opposite influence on the benthic community, and because trematode infections sometimes compromise the survival rate of gastropods (Mouritsen and Poulin, 2002), the indirect effect of parasite-induced host mortality and behaviour will under in situ conditions act in concert and reinforce the observed pattern of decreasing diversity of (some) primary producers and increasing diversity of (smaller) secondary producers as a function of parasitism. However, populations of marine invertebrates are rarely eradicated by their parasites, which appears necessary in the present host-parasite system for the community impact of parasite-induced host mortality to approach that of altered host behaviour. It follows that the community impact of changed host behaviour (the trait-mediated effects) by far exceeds that of host population regulation (the densitymediated effects) in this intertidal ecosystem.

There exist only few field-experimental studies demonstrating comparable community-wide indirect effects of parasitism. Mouritsen and Poulin (2005a, 2006) showed that increased surfacing behaviour and reduced mobility of trematode-infected New Zealand cockles Austrovenus stutchburyi significantly altered the surrounding benthic community of primary and secondary producers (see also Thomas et al., 1998, Mouritsen and Poulin, 2005b). Regarding the animals, parasitism generally increased diversity in line with the present results. Wood et al. (2007) have shown that infections by the trematode Cryptocotyle lingua result in reduced consumption of ephemeral macroalgae by the periwinkle Littorina littorea, in turn changing the in situ community structure of macroalgae. Also, studies by Pennings and Callaway (1996) and Callaway and Pennings (1998) showed substantial effects on the non-host community of salt marsh plants by the parasitic plant Cuscuta salina: the parasite decreased the biomass of the primary host and superior competitor, Salicornia virginica, thereby increasing abundance and diversity of less competitive species. Outside the intertidal zone, Marvier (1998) demonstrated a similar effect by the hemiparasitic plant Triphysaria pusilla (root parasite) in a Californian prairie community. From a freshwater system, Bernot and Lamberti (2008) showed that increased grazing activity by trematode-infected snails (Physa acuta) significantly changed the community structure of periphyton.

Together, these studies and the present results emphasize the importance of parasitism as a determinant of community composition and function. The emerging pattern points at elevated species diversity as a consequence of parasitism, but also that this, aside from the level of parasitism, depends on the trophic level in focus, host density, and whether we are dealing with trait- or host density-mediated effects.

The challenges for the future will be to further evidence the community-wide impact of parasitism in a broader range of ecological communities, and to unravel the relative importance of trait- and host density-mediated effects. This should be done, not only by focusing on a single promising host-parasite system, but by integrating a wider range of host-parasite systems co-occurring in a given community of plants and animals.

\section{Acknowledgements}

We wish to thank I. Buss, S. Petersen, T. Cedhagen, K. Sabbe, G. Klein, L. Flensborg, L. T. Mouritsen, M. Schmidt and K. S. Beck for technical assistance, and referees for constructive comments on the manuscript. The study was supported financially by the Carlsberg Foundation (KNM). [ST]

\section{Appendix 1}

Classes and species/species-groups of meiofauna and juvenile macrofauna encountered in samples from the upper $1.8 \mathrm{~cm}$ of the caged sediment, with indication of size range (obtained by wet sieving) and origin of treatment. Treatments are: (1) No snails (Hydrobia ulvae), (2) 38 uninfected snails cage $e^{-1}$, (3) 75 uninfected snails cage ${ }^{-1}$, (4) 75 snails cage $^{-1}$ (33\% infected) and (5) 75 snails cage ${ }^{-1}$ (100\% infected). Size ranges are: (1)>500 $\mu \mathrm{m},(2)[250 ; 500] \mu \mathrm{m},(3)[125 ; 250] 6 \mu \mathrm{m}$ and (4) $[63 ; 125] \mu \mathrm{m}$. 'All' denotes that the species/species-group is encountered in all treatments or size ranges.

\begin{tabular}{|c|c|c|}
\hline Class/species & Treatment & Size range \\
\hline \multicolumn{3}{|l|}{ Foraminifera } \\
\hline Ammonia sp. & All & All \\
\hline Bolivina sp. & 1 & 2 \\
\hline Elphidium $s p$ & All & All \\
\hline Elphidium williamson & All & $2,3,4$ \\
\hline Elphidiidae sp. & All & All \\
\hline Nonionidae sp. & All & $2,3,4$ \\
\hline Nemertea spp. & All & $2,3,4$ \\
\hline \multicolumn{3}{|l|}{ Nematoda } \\
\hline Nematoda spp. 1 & All & All \\
\hline Nematoda spp. 2 & All & All \\
\hline \multicolumn{3}{|l|}{ Gastropoda } \\
\hline Hydrobia ulvae & All & All \\
\hline \multicolumn{3}{|l|}{ Bivalvia } \\
\hline Cerastoderma edule & $2,3,5$ & 1 \\
\hline Corbula gibba & All & All \\
\hline Macoma balthica & 1,5 & 2 \\
\hline Mya arenaria & 5 & 3 \\
\hline \multicolumn{3}{|l|}{ Polychaeta } \\
\hline Capitella capitata & 4,5 & 1,3 \\
\hline Hediste diversicolor & 1,4 & 1,4 \\
\hline Polydora ligni & $0,1,2,5$ & 1,2 \\
\hline Pygospio elegans & All & 1,3 \\
\hline Tharyx marioni & All & All \\
\hline \multicolumn{3}{|l|}{ Oligochaeta } \\
\hline Naididae spp. & $1,2,4,5$ & $1,2,3$ \\
\hline Pelescolex benedeni & All & $1,2,3$ \\
\hline Ostracoda spp. & All & All \\
\hline \multicolumn{3}{|l|}{ Copepoda } \\
\hline Cyclopoid sp. 1 & All & $2,3,4$ \\
\hline Cyclopoid sp. 2 & All & All \\
\hline Harpacticoid spp. & All & 3,4 \\
\hline \multicolumn{3}{|l|}{ Amphipoda } \\
\hline Corophium volutator & $1,2,3,4$ & 3,4 \\
\hline
\end{tabular}

\section{References}

Andersen, T.J., 2001. Seasonal variation in erodability of two temperate microtidal mudflats. Est. Coast. Shelf Sci. 53, 1-12.

Andersen, T.J., Jensen, K.T., Lund-Hansen, L., Mouritsen, K.N., Pejrup, M., 2002. Enhanced erodibility of fine-grained marine sediments by Hydrobia ulvae. J. Sea Res. 48, 51-58.

Austen, M.C., Widdicombe, S., 2006. Comparison of the response of meio- and macrobenthos to disturbance and organic enrichment. J. Exp. Mar. Biol. Ecol. 330, 96-104.

Begon, M., Townsend, C.R., Harper, J.L., 2006. Ecology, 4th ed. Blackwell Publishing, Oxford. Bernot, R.J., Lamberti, G.A., 2008. Indirect effects of a parasite on a benthic community: an experiment with trematodes, snails and periphyton. Freshw. Biol. 53, 322-329.

Blanchard, G.F., 1991. Measurement of meiofauna grazing on microphytobenthos: is primary production a limiting factor? J. Exp. Mar. Biol. Ecol. 147, 37-46.

Buffan-Dubau, E., Carman, K.R., 2000. Diel feeding behavior of meiofauna and their relationships with microbial resources. Limnol. Oceanogr. 45, 381-395.

Callaway, R.M., Pennings, S.C., 1998. Impact of a parasitic plant on the zonation of two salt marsh perennials. Oecologia 114, 100-105.

Deblock, S., 1980. Inventaire des trématodes larvaires parasites des mollusques $\mathrm{Hy}$ drobia (Prosobranches) des côtes de France. Parassitologia 22,1-105 (in French).

Dyson, K.E., Bulling, M.T., Solan, M., Hernandez-Milian, G., Raffaelli, D.G., White, P.C.L., Paterson, D.M., 2007. Influence of macrofaunal assemblages and environmental heterogeneity on microphytobenthic production in experimental systems. Proc. $\mathrm{R}$. Soc. B 274, 2547-2554. 
Epstein, S.S., 1997. Microbial food web in marine sediments. 1. Trophic interactions and grazing rates in two tidal flat communities. Microb. Ecol. 34, 188-198.

Fernandez, J., Goater, T.M., Esch, G.W., 1991. Population-dynamics of Chaetogaster limnaei limnaei (Oligochaeta) as affected by a trematode parasite in Helisoma anceps (Gastropoda). Am. Midl. Nat. 125, 195-205.

Fredensborg, B.L., 2001. Infestation patterns of Hydrobia ulvae on an intertidal mudflat as a function of the abundance and distribution of birds. MSc.-dissertation, University of Aarhus, pp. 15-44.

Heath, M.R., Richardson, K., Kiørboe, T., 1990. Optical assessment of phytoplankton nutrient depletion. J. Plankton Res. 12, 381-396.

Krebs, C.J., 1999. Ecological methodology, 2nd ed. Addison-Wesley Educational Publishers, Menlo Park, California.

Lorentzen, C.J., 1967. Determination of chlorophyll and pheo-pigments: spectrophotometric equations. Limnol. Oceanography 12, 343-346.

Marvier, M.A., 1998. Parasite impact on host communities: plant parasitism in a California coastal prairie. Ecology 79, 2616-2623.

Meysman, F.J.R., Middelburg, J.J., Heip, C.H.R., 2006. Bioturbation: a fresh look at Darwin's last idea. Trends Ecol. Evol. 21, 687-695.

Montagna, P.A., Blanchard, G.F., Dinet, A., 1995. Effect of production and biomass of intertidal microphytobenthos on meiofaunal grazing rates. J. Exp. Mar. Biol. Ecol. $185,149-165$.

Mouritsen, K.N., Jensen, K.T., 1994. The enigma of gigantism - Effect of larval trematodes on growth, fecundity, egestion and locomotion in Hydrobia ulvae (Pennant) (Gastropoda, Prosobranchia). J. Exp. Mar. Biol. Ecol. 181, 53-66.

Mouritsen, K.N., Poulin, R., 2002. Parasitism, community structure and biodiversity in intertidal ecosystems. Parasitology 124, S101-S117.

Mouritsen, K.N., Poulin, R., 2005a. Parasites boost biodiversity and changes animal community structure by trait-mediated indirect effects. Oikos 108, 344-350.

Mouritsen, K.N., Poulin, R., 2005b. Parasitism can influence the intertidal zonation of non-host organisms. Mar. Biol. 148, 1-11.

Mouritsen, K.N., Poulin, R., 2006. A parasite indirectly impacts both abundance of primary producers and biomass of secondary producers in an intertidal benthic community. J. Mar. Biol. Assoc. UK 86, 221-226.

Mouritsen, K.N., Jensen, T., Jensen, K.T., 1997. Parasites on an intertidal Corophium-bed: factors determining the phenology of microphallid trematodes in the intermediate host populations of the mud-snail Hydrobia ulvae and the amphipod Corophium volutator. Hydrobiologia 7 (355), 61-70.

Orvain, F., Sauriau, P.-G., 2002. Environmental and behavioural factors affecting activity in the intertidal gastropod Hydrobia ulvae. J. Exp. Mar. Biol. Ecol. 272, 191-216.

Orvain, F., Le Hir, P., Sauriau, P.-G., 2003. A model of fluff layer erosion and subsequent bed erosion in the presence of the bioturbator, Hydrobia ulvae. J. Mar. Res. 61, 823-851.

Orvain, F., Sauriau, P.G., Bacher, U., Prineau, M., 2006. The influence of sediment cohesiveness on bioturbation effects due to Hydrobia ulvae on the initial erosion of intertidal sediments: a study combining flume and model approaches. J. Sea Res. 55, 54-73.
Pennings, S.C., Callaway, R.M., 1996. Impact of a parasitic plant on the structure and dynamics of salt marsh vegetation. Ecology 77, 1410-1419.

Platt, H., Warwick, R.M., 1988. Free living marine nematodes. In: Brill, E.J. (Ed.), Part II, British Chromadorids. Dr. W. Backhuys, New York.

Poulin, R., 2007. Evolutionary ecology of parasites, 2nd ed. Princeston University Press, Princeston.

Poulin, R., Mouritsen, K.N., 2003. Large-scale determinants of trematode infections in intertidal gastropods. Mar. Ecol. Prog. Ser. 254, 187-198.

Power, M.E., Tilman, D., Estes, J.A., Menge, B.A., Bond, W.J., Scott Mills, L., Daily, G., Castilla, J.C., Lubchenco, J., Paine, R.T., 1996. Challenges in the quest for keystones. Bioscience 46 (9), 609-620.

Rasmussen, C., Dalsgaard, K., 2005. Detaljeret metodebeskrivelse til laserdifraktion af jord- og sedimentprøver. Aarhus Universitetsforlag, Aarhus. (in Danish).

Reise, K., 1985. Tidal flat ecology. An experimental approach to species interactions. Springer-Verlag, New York

Rodgers, J.K., Sandland, G.J., Joyce, S.R., Minchella, D.J., 2005. Multi-species interactions among a commensal (Chaetogaster limnaei limnaei), a parasite (Schistosoma mansoni), and an aquatic snail host (Biomphalaria glabrata). J. Parasitol. 91, 709-712.

Scott, M.E., Dobson, A.P., 1989. The role of parasites in regulating host abundance. Parasitology Today 5, 176-183.

Thomas, F., Renaud, F., de Meeûs, T., Poulin, R., 1998. Manipulation of host behaviour by parasites: ecosystem engineering in the intertidal zone? Proc. R. Soc. Lond. Ser. BBiol. Sci. 265, 1091-1096.

Tietjen, J.H., 1969. The ecology of shallow water meiofauna in two New England estuaries. Oecologia 2, 251-291.

Tita, G., Desrosiers, G., Vincx, M., Nozais, C., 2000. Predation and sediment disturbance effects of the intertidal poluchaete Nereis virens (Sars) on associated meiofaunal assemblages. J. Exp. Mar. Biol. Ecol. 243, 261-282.

Tompkins, D.M., Dobson, A.P., Arneberg, P., Begon, M.E., Cattadori, I.M., Greenman, J.V., Heesterbeek, H., Hudson, P.J., Newborn, D., Pugliese, A., Rizzoli, A.P., Rosã, R., Rosso, F., Wilson, K., 2002. Parasites and host population dynamics. In: Hudson, P.J., Rizzoli, A., Grenfell, B.T., Heesterbeek, H., Dobson, A.P. (Eds.), The ecology of wildlife diseases. Oxford University Press, Oxford, pp. 45-62.

Trussell, G.C., Ewanchuk, P.J., Bertness, M.D., 2003. Trait-mediated effects in rocky intertidal food chains: predator risk cues alter prey feeding rates. Ecology 84 629-640.

Widdicombe, S., Austen, M.C., 1999. Mesocosm investigation into the effects of bioturbation on the diversity and structure of a subtidal macrobenthic community. Mar. Ecol. Prog. Ser. 189, 181-193.

Widdows, J., Brinsley, M., 2002. Impact of biotic and abiotic processes on sediment dynamics and the consequences to the structure and function of the intertidal zone. J. Sea Res. 48, 143-156.

Wood, C.L., Byers, J.E., Cottingham, K.L., Altman, I., Donahue, M.J., Blakeslee, A.M.H. 2007. Parasites alter community structure. Proc. Natl. Acad. Sci. 104, 9335-9339. 